\title{
Axiological component of professional readiness of a modern teacher to work in the aspect of the cross-border region
}

\author{
Nadezhda Bulankina ${ }^{1 *}$. Konstantin, Umbrashko ${ }^{1}$, Li Nan ${ }^{2}$ and Sun Yumen ${ }^{2}$ \\ ${ }^{1}$ Novosibirsk Institute of Professional Skills Improvement and Vocational Retraining of \\ Education Workers 630007, Novosibirsk, Russian Federation \\ ${ }^{2}$ Jiangsu Normal University, 221009, Xuzhou, China
}

\begin{abstract}
The article deals with some features of the value component of the teacher's professional readiness to solve urgent problems of modern school in the aspect of new educational guidelines. The authors' project explores the possibility of cultivating humanitarian practices to renovate the professional educational space of the Siberian cross-border region on the basis of training and retraining of foreign language teachers. The conclusion is based on the positive results of the introduction of cultureoriented practices of interactive interaction and mutual influence of linguists, allowing to create favorable conditions for cultural selfdetermination of students in a socio-cultural situation that requires understanding and respect for the cultural identity of others while preserving their own cultural identity by means of linguistic culture.
\end{abstract}

\section{Introduction}

The axiological component of the teacher's professional readiness is understood as an integrative personal new formation, which underlies the formation of cultural selfdetermination of the individual in a specially organized professional educational environment of the participants of cultural interaction [1], which requires constant and systematic updating in the regions of cross-border type. The problems of educational activities are associated with numerous and diverse innovations in modern Russian society, which at the same time form the educational context for discussion.

A number of studies have noted the crisis of education, characterized by a shortage of highly qualified teaching staff, as well as the reluctance of young people to associate their professional activities with pedagogical work. As a result, the personnel shortage, especially in cross-border regions, as we see the Siberian region, where there is a decrease in the level of language training of students and graduates in the space of intensive migration processes $[2,3,4,5,6,7]$. It is important to emphasize that the Russian school, without losing optimism and perseverance in achieving positive educational outcomes, choosing the path of positive transformation through the implementation of modern challenges to education, at the state level, carries out a systematic search of the solution of

\footnotetext{
${ }^{*}$ Corresponding author: nebn@yandex.ru
} 
the tasks of professional growth of a modern teacher, as an important factor for cultural self-determination in the multicultural world. This concerns the introduction of new standards of higher pedagogical education, and the transition to a modular system of additional professional programs, and updating the principles of mentor and tutorial practices, as well as activities in the format of distance learning and online education. The necessity of cultivating the principle of "education through life" and taking into account the peculiarities of recurrence in education, with periods of training and teachingб is increasingly stated $[8,9,10,11]$.

The analysis of the results of these studies, conducted by domestic and foreign authors, allows us to consider culture as a value from the viewpoint of the axiological approach; and transforming a must into realia, to transfer cultural patterns into the inner world of a personality. That is why, for the authors of this article, the starting point of the study of the problem context of the region of cross-border character is the deployment of the third Millennium realities of the cultural mission of education (Bondarevskaya, Krylova, Curtis]. This culture-creative role is seen in updating the content of technological professional environment of interaction of specialists in the system of continuous and recurrent education, recognizing the structural and substantive core of the novel ideology of education as the development of the value component of the individual, his civil, sociocultural and solidarity initiatives, multicultural freedom, moral and legal responsibility of the individual $[2,4,8,9]$.$] . As is the case, such education implies the organization of$ speech habits and communication in the system of professional training of the individual $[10,11,12,13]$, and professional development of the teacher $[14,15,16]$ on humanistic principles. Becoming socially valuable, the axiological context of the developing environment in terms of professional development and skills of a modern teacher finds justification in the framework of the national project "Teacher of the Future". Thus, the task of preserving these values in education and in society is increasingly becoming a priority for everyone who deals with another person, in our case, for any teacher [17].

The purpose of this article is to analyze some real possibilities of the Region in the aspect of formation of professional competence of a linguist to solve the problems of the foreign language education as part of the multicultural space. The main problem of the research is the actualization of the system formation of students ' orientation to cultural self-determination (CS) in the axiological multicultural space. At the same time, it becomes important to determine important conditions for creating and cultivating such a model of the developing environment in the system of professional retraining of a teacher that uses both the humanistic realities of modernity and pedagogical reality.

\section{Concept and methodology of the study}

The empirical array is based on literature sources on the above problem (main concept: due to the importance of the phenomenon of the humanitarian component of education, the poly-linguistic component of the multicultural global information world becomes a priority for the formation of pedagogical practices as a methodological point in cross-border regions); a set of materials on "National projects" and state documents on education; domestic and foreign educational publications in foreign languages, Russian and international additional professional educational programmes for the system of mentoring and professional retraining in the framework of the project "Teacher of the Future"; speech products. Experimental base covers advanced courses: Refresher courses for both retraining and advanced teachers (25courses), regional schools (500 teachers, $25 \%$ of the total number of foreign language teachers in the Region). 
Research methods include the analysis of literature on the problem, experiment, including observation- modelling, content analysis of speech products, interpretation, and statistical processing.

\section{Results of the study and their discussion}

At the first stage, the aim is to comprehend the results of the analysis of literature on the creation of conditions for actualization of the axiological component of professional readiness of a teacher in the innovative professional environment of interaction of specialists in the field of foreign language education in the system of continuous education of the cross-border region. The analytical work allows the authors to construct a concept that determines the methodological guidelines for the study of the phenomenon of axiological component of professional readiness of teachers in the framework of cultural, value and communicative-activity approaches to the organization and content of technological development of the environment of interaction between participants of the educational process.

The most important position regarding the personal needs that concern the formation of professional readiness of the teacher for the solution of the problems of humanitarian character in the conditions of the cross-border region as a complex of readiness, in the constantly updated space of pedagogical reality. At the same time, when modeling the developing professional environment of interaction between specialists, it is important to cultivate methodological and subject readiness as a basis for motivational readiness of the teacher to design communicative socially significant pedagogical activity. Moreover, when modelling the educational communicative situations and practices, it is significant to adopt cultural patterns of speech and communicative strategies of productive interaction of the participants of cultural self-determination in the educational space.

As is the case, CS is considered as a process of conscious choice of languages of the educational space as instruments of the linguistic self-realization of a person. As a result, the cultivation of national, linguistic self-consciousness, social identity and the design of the individual trajectory of personal development (in life, in the profession). This process is characterized by the subject's awareness of their cultural identity in terms of assigning values when choosing expressive means of culture, languages as an integral part of the native and world culture, as well as the ability to constant spiritual and moral renewal in the space of verbal//non-verbal, artificial/natural languages, multilingualism, multicultural education and the world. As a technology, CS assumes the creation of the integrative educational space of development tasks of communicative character [17].

At the second stage of the research the aim is to study and generalize pedagogical experience, organization of scientific observation of the practice of foreign language education in the region. As a result, we obtained empirical data on the investigated personal needs of the CS of a linguist, on the level of formation of the axiological component of professional readiness to solve urgent problems of modern education on the basis of the results of diagnostics of methodological and subject/language readiness, as well as motivational readiness for professional growth. According to the results of the input monitoring sections (tests, essays, essays, oral and written surveys), there is: a) low level of proficiency in foreign language speech of $85 \%$ of specialists, b) ignorance of the psychological, pedagogical and methodological foundations of the formation and functioning of skills and abilities in speaking and listening, writing and reading of $78 \%$ of teachers. According to the results of the survey among the reasons for this situation should be called: a) inadequate needs of the region for the number of graduates in almost every school from the years of 2000 to the present; b) overload of foreign/English teachers, currently the weekly load is 30 hours and above plus classroom management; c) lack of 
time for self-education, and, as a consequence, the lack of systematic work of the teacher to improve language and speech skills in $85 \%$ of students, the lack of habit/tradition to refer to the original literary sources for high level of communicative competence in $90 \%$ of teachers; e) lack of qualified personnel for the introduction of the second and third foreign languages (exclusion of multilingualism and poly-cultures in schools); e) insufficient provision of modern technologies of education (IT).

The data allow us considering the need for updating the realities of the educational process, from different points of view, and for expanding the boundaries of the use of cultural meanings of educational practices in the name of solving humanistic tasks, set at the state level, as well as to identify means of neutralizing the problem context of the region in the aspect of the problem phenomenon. In particular, at this stage, teaching devices were created for teachers in the format of online and distance learning, including a system of communicative situations and methodological development tasks that reflect positive communicative strategies of productive interaction of the participants in the educational process. They were based on the following provisions:

The first position comes from the principles of communicative-activity approach, according to which human communication, understanding and mutual understanding, mutual influence and interaction of people as a value, should be in the area of close attention to the language as a priority, but not the only tool of communication. In particular, if language is considered as one of the humanistic realities of polyphonic and multicultural conventional space. The second one relates to the CS technology, which involves the creation of an integrative holistic educational space of development tasks of communicative and activity nature. The third position is aimed at implementing the principles of humanistic philosophy of education, according to which school lessons of any academic discipline Humanities/language component is not only a compulsory element of the educational process, but an integral part of the overall communication culture and the participants. Moreover, the language culture and the communicative component of the educational process as a whole involve the use of expressive means of culture as tools of knowledge and self-knowledge, positive communication to understand and harmonize interaction and mutual influence, aimed at educating a citizen of Russia, a patriot, enriched with spiritual and moral values.

The above theoretical and methodological positions have formed the basic requirements for a development model of the professional experience of specialists in the space of foreign language education in the region determined the development of innovative educational environment through additional educational programs.

At the third stage of the research, the aim is to introduce a model of development professional environment as a continuous integrative space of tasks of communicative and activity nature. The task of this stage includes the approbation of the mechanism of designing educational situations of communicative nature by students, on the example of authors' teaching devices, developed in the format of questions and tasks of developing nature on the topics:

Communicative aspects of qualitative management of innovative development and educational activities, 2016; Readiness of the teacher-humanitarian to implement the concepts of school language education, 2017; communication technologies of CS in modern humanitarian education in the context of the requirements of the exams, 2018. Neutralization of problem areas of professional (methodological and subject) readiness of the teacher to solve urgent problems of foreign language education of students is carried out in accordance with the developed principles of cultural self-determination in the educational process of urban and regional schools in the Region.

The programme of the experiment includes the following milestones: monitoring sections, input and final, reflecting the results of understanding in the content analysis of 
oral and written answers of teachers who performed tests (in foreign/English) and tasks of methodical nature to understand modern methodology of foreign language education and its effectiveness in the educational process (by means of the database of the results of the exam); b) classes for teachers of English in the system of course training and retraining, the main purpose of which is to neutralize the problems of language and communicative competence of a teacher; c) organization the city and regional scientific and methodological seminars at the best schools of the Novosibirsk region, the target setting of which is a critical analysis of the products of communication in classes (both native and foreign languages).

At this stage, the program of the course of training specialists and retraining of nonspecialists was organized as a unified integrative space of problem-solving tasks where the students demonstrate the degree of professionalism - knowledge, skills and abilities required in the professional modern ELT, to improve their professional skills. The content of the software was presented by the authors' teaching devices, which fully reflected the system of problem tasks for the formation/improvement of speech habits of students, as well as authentic teaching materials for teachers "Career Paths" (Career development/growth, Express Publishing). Moreover, the following important factors and conditions, which are under discussion, become a priority in the formation of innovative professional environment of interaction of specialists as a united integrative space of the problem under discussion.

Cognitive activity of students is organized as a process of mastering new cultural content, not only the culture of the people, their culture values and traditions, but also the mastery of language as part of culture. Activity in terms of personal development is aimed at mastering the psychological content through the disclosure of abilities, which are based on the improvement of mental functions of the individual - perception, imagination, semantic memory, etc. on new content in order to maintain the psychological balance of the direct participants of the educational process. Mastering the pedagogical content (moral, moral, ethical aspects) involves primarily increasing the level of responsibility of teachers for the results of their own learning and self-education. Educational activity as cooperation of listeners is presented as mastering social content, social in the sense that speech skills are assimilated as a means of communication in society, in a society where any student/listener should know and be able to implement the functions that each of the speech skills and communication in General have. The results of the activities of teachers are reflected in the articles, in the participation in the projects of publishers, in the preparation of collective teaching devices.

The proposed model is meaningfully fit in and is directly related to the adoption of the National project "Education". According to the presidential Decree "On the national goals and strategic objectives development of the Russian Federation for the period up to 2024" from 07.05.2018 No. 204 in the Novosibirsk region in the framework of the national project "Education" it is planned to implement 10 regional projects: "Modern school", "the Success of every child", "Supporting families having children", "Digital learning environment", "the teacher of the future", "Young professionals (improving the competitiveness of vocational education)", "New opportunities for everyone", "Social activity", "Export of education", "Social lifts", "working" for the project "Teacher of the future". This thesis is used as a leading position on the assessment of existing programmes (DPOP) and the development of the content of constantly updated corpus of DPOP in the system of recurrent and continuing education in the Humanities (languages). In turn, it is the DPOP that in this study have become the basis for creating favorable conditions for innovative professional environment of interaction of specialists at the regional level.

As a result of the experiment (2015-2019), the introduction of a model of developing professional environment of interaction, which is based on updated work programs, as well 
as the analysis of the effectiveness of scientific and methodological support of the educational process in the aspect of technological content of additional educational programmes. The carried out cycle of actions for realization of principles of cultural selfdetermination of the teacher-humanitarian in the professional educational environment allows replicating the model in the regional system of recurrent education of a teacherphilologist. As is the case, the authors of this study have come to the conclusion that, on the basis of a critical analysis of the survey results, it can be argued that in pedagogical theory and practice, the language component of education as a reality does not work in full. But this does not mean that Russian school should not move in the positive direction, maintaining the educational status of their institution only formally using the language (in all its forms) as a tool of expressive communication, formulation of tasks, presentation of information, programs, plans, for occupations of different types, etc.); languages in education, a word, gesture, facial expressions, language, physical experiment, the visual language of information of the language of the author' text in the textbook, the language of the subjects of the educational process, i.e. multilingualism as tools, first of all, for selfimprovement, self-education and self-education through life, are designed to work in the space of each modern lesson.

\section{Conclusion}

The beginning of the third millennium in Russia is characterized by significant complications of social life, generating a manifestation of instability of human life. In particular, the deformation of public consciousness of the importance of traditional values, ideals, social ties, forms of real communication and means of preserving human's life leads to the fact that a person should strive to adequately assess of the situation and determine his attitude to it, as well as his place in the format the of changes.

The positive results of this research allow us to formulate some optimistic theses about the Russian pedagogical reality:

-the development of personal qualities such as creativity, initiative and responsibility, independence, combined with high education and good breeding, psychological and moral stability, as well as positive citizenship, should be decisive in the fate of the individual and the country as a whole;

-the need for the formation of social identity of the citizen of Russia and the development of cultural and historical thinking of the personality of students, the importance of creating optimal conditions for the manifestation of national and crosscultural consciousness in the multicultural and multilingual world, as well as some other values and orientations in the desired aspect are fundamentally important in terms of increment of personal, always unique and unrepeatable, state and standing of a person in the space of "the ambiguity of mind" (I. Ilyin, 1943);

-human-forming function and cultural mission of modern education is a priority goal and the task of the whole society in the conditions of ambiguous critical socio-cultural situations;

-these two humanistic realities of education, which are based on multilingualism as an expressive means of culture, through which education, development and training are carried out, require increased attention from the developers of the strategy for the development of educational practices in General, and theorists and teachers-practitioners;

-theoretical and methodological support with the help of effective, from the point of view of humanitarian orientation, pedagogical cultural-oriented practices in education becomes especially important against the background of constantly changing world sociocultural situation, its instability, uncertainty and psychological tension. 


\section{References}

1. N. Bulankina, Humanitarian self-organization of personality. Philosophical reflections (NSTU publishing house, Novosibirsk, 2013)

2. N. Bulankina., O. Ivanova, Design of innovative space of humanitarian education in modern school: textbook for teachers (Publishing house NIPKIPRO, Novosibirsk, 2014)

3. M. Buzsky, Individualization of education as a priority basis of pedagogical activity. Theory and practice of individualization of education: collection of lectures (Print, Volgograd, 2013).

4. N. Sergeev., V. Serikov, Pedagogical activity and pedagogical education in innovative society (Logos, Moscow, 2013)

5. Individualization of education as a priority basis of pedagogical activity. Theory and practice of individualization of education: collection of lectures (Print, Volgograd, 2013)

6. S. Ter-Minasova, Language and intercultural communication (SLOVO, Moscow, 2008)

7. S. Ter-Minasova, War and the world of languages and cultures (SLOVO, Moscow, (2008)

8. G. Filonov, Pedagogy, 7, 43-50 (2013)

9. S. Nieto, Affirming diversity: The sociopolitical context of multicultural education (White Plains, NY, 1992)

10. L. Glass, Confident conversation. How to talk in any business or social situation (J.Piatkus, London, 1991)

11. O.D. Fedotova, EDULEARN Proceedings, 45-54 (2012)

12. Ja.M. Jaafar, French Language. International Journal of Academic Research. 2(3), 238-240 (2010)

13. J. Harmer, How to teach English (Pearson, 2011)

14. N. Bulankina, International Journal of Academic Research. 2(3), 253-255 (2010)

15. N. Bulankina, S. Bracher, K. Umbrashko, Psychology of education in polycultural space, 2(46), 72-77 (2019)

16. K.Curtis, Personality formation, 3, 18-21 (2016)

17. N.Bulankina, Personality Formation, 2, 78-87 (2016) 